\title{
Unusual Warming in the Coastal Region of Northern South China Sea and Its Impact on the Sudden Intensification of Tropical Cyclone Tembin (2012)
}

\author{
Zhe-Wen Zheng \\ Institute of Marine Environmental Science and Technology and Department of Earth Science, National Taiwan Normal University, \\ Taipei 11677, Taiwan \\ Correspondence should be addressed to Zhe-Wen Zheng; zwz@ntnu.edu.tw
}

Received 27 October 2013; Accepted 28 November 2013; Published 29 January 2014

Academic Editor: Yuriy Kuleshov

Copyright (c) 2014 Zhe-Wen Zheng. This is an open access article distributed under the Creative Commons Attribution License, which permits unrestricted use, distribution, and reproduction in any medium, provided the original work is properly cited.

\begin{abstract}
Tropical cyclone Tembin (2012) passed twice and made landfall over south tip of Taiwan in August 2012. During its passage, an unusual sea surface warming was generated at $22.5^{\circ} \mathrm{N}, 117^{\circ} \mathrm{E}$ in the coastal region of northern South China Sea. Subsequently, Tembin passed over this extreme warming region and its intensity was enhanced drastically and suddenly from Category 1 to Category 3 within less than 1-day time interval. This unusual warming seems to largely prompt the intensification of Tembin. Next, the relationship between this extreme warming and rapid intensification of Tembin is identified by atmospheric model Weather Research and Forecast (WRF) with updated time-varying lower boundary condition. In addition, given the tight relationship between generation of unusual warming in the shore region and following possible TC intensification, a series of numerical experiments based on oceanic model Regional Oceanic Modeling System (ROMS) were designed and executed to resolve the possible generated mechanism of the extreme warming. The results indicate that a distinct positive short-wave radiation influx anomaly may dominate the generation of the unusual warming in the shore region during Tembin's passage. This result is validated by the distributions of free cloudy coverage shown in satellite infrared images.
\end{abstract}

\section{Introduction}

The phenomena of sea surface temperature (SST) cooling in response to a tropical cyclone (TC) passage have been investigated comprehensively in numerous studies (e.g., [15]). TC's passage has been shown to markedly lower the sea surface temperature (SST) under certain circumstances [1-4, $6,7]$. Furthermore, because evaporation and conduction are directly dependent upon the air-sea temperature difference, SST drops would directly determine the energy fed into the storm from the ocean [8] and thus their impact on TC intensity evolutions [9-11].

However, on the contrary, the generation of an unusual sea surface warming during a TC passage does not attract too much investigative attention [12], because they are much rare relatively to the generation of a cooling case. Its impact on the TC intensity changes is not even clear sufficiently yet. Given the same concept but in a different way, that warming may cause TC intensification through feeding more energy from ocean to TC through air-sea exchange. Moreover, extreme warming which occurred near the coastal region is extraordinary important, because it may cause TC rapid intensification just prior to making landfall in heavily populated coastal region. In other words, the generation of that warming near the coastal region may directly link to the possible increase of threats of TC on those people and economic activity surrounding the coastal region.

Tembin (2012) lingered over northern South China Sea (NSCS) from 24 August to 27 August and passed through an extreme warming patch at $22.5^{\circ} \mathrm{N}, 117^{\circ} \mathrm{E}$ on 25 August. After encountering the distinct warming patch generated along northeastern SCS, intensity of Tembin is enhanced drastically and suddenly from category 1 to category 3 within less than 1-day time interval. Air-sea interaction which occurred during the passage of Tembin provides us with a unique opportunity to clarify the relationship between that coastal 
warming and the consequential possible intensification of TCs. One of the main goals of this work is to identify the causation between warming occurring in the coastal region and following TC intensification from a more convinced, dynamic based tool/perspective. On the other hand, we further hope to clarify the possible mechanism(s) causing the generation of warming within the coastal region that eventually may trigger a TC rapid intensification just prior to its landfall and thus may increase the threats to those economical activities and people living near the coastal lowlying region [13].

\section{Data and Methods}

In this work, the cyclonic track and intensity data are obtained from the Unisys weather (http://weather.unisys .com/hurricane/). Microwave SST products retrieved from Tropical Rainfall Measuring Mission (TRMM) Microwave Imager (TMI) are used to characterize the evolution of unusual warming in the shore region generated during Tembin's passage [2]. In Section 3, numerical experiments using atmospheric model Weather Research and Forecast (WRF) are conducted to evaluate the impact of SST warming occurring in the coastal region on the TC intensity changes of Tembin. Initial and boundary conditions for WRF were produced from Global Forecast System (GFS) FNL global analysis field with a $1^{\circ} \times 1^{\circ}$ spatial resolution in a 6-hour temporal interval. Meanwhile, a series of numerical experiments based on oceanic numerical model Regional Ocean Modeling System (ROMS) were conducted in Section 4 to help the understanding of the generation of extreme warming in the coastal region of northern SCS (NSCS) during Tembin's passage. Initial and boundary condition for ROMS were derived from HYCOM/NCODA system outputs [14]. Heat and momentum fluxes in ROMS were calculated from atmospheric parameters obtained from GFS (available at http://nomads.ncdc.noaa.gov/) with a bulk formula during the model run. More details about the configuration of ROMS model are given by Zheng et al. [15].

\section{Warming versus TC Rapidly Intensification}

3.1. Observations. Figure 1(a) shows the SST collected on 25 August. One can see that there is one distinct warming occurring in the coastal region along the NSCS continental shelf at around $22.5^{\circ} \mathrm{N}, 117.5^{\circ} \mathrm{E}$, though the SST is not very uniform in this region because of the passage of previous TC Kai-Tak (12-17 August). Relative to cooling also caused by Tembin's passage, the extreme warming generated at the coastal region along NSCS is more distinct and unique. Figures 1(b)-1(f) show the corresponding SST evolution during Tembin's passage and demonstrate the generation and evolution of the unusual warming in the coastal region. From Figure 1, one can see that the warming patch grows up from August 22 to August 25 and starts to decay on August 26. Finally, it disappears while the cooling in response to Tembin passage took place.
In addition to the generation of unusual warming in the coastal region along the continental shelf of NSCS, more interesting is the relationship between the warming and consequential TC intensity changes. Figure 2 shows the TC intensity change of Tembin before and after encountering the warming patch located at the coastal region. Form Figure 2, it is evident that from 12:00 UTC 25 August to 6:00 UTC 26 August, after Tembin encountering the distinct warming patch occurring along the NSCS continental shelf, the strength of Tembin rapidly intensified from Category 1 to Category 3 within 18 -hour temporal interval. Next, after passing the Dongsha atoll, the strength of Tembin weakened steadily until it leaves the study area. This result suggests a crucial scenario that the extreme coastal warming may serve as a booster for increasing the intensity of a TC in a very short time period. It is worth claiming that this possible intensification of TC intensity may directly increase the threats to those people living in the coastal low-lying region, because this unusual warming occurs in the coastal region just prior to the landfall of a given TC.

3.2. Simulations. Here, the tight relationship between surface warming and following possible TC rapid intensification shown in previous section by observations is further validated. In this section, WRF is applied to elucidate the effect of different SST on TC intensity changes. For comparison, two numerical experiments based on WRF were designed and executed. In both experiments, all parameters configurations were set by default values as provided by WRF community. To reveal the effect resulting from lower boundary condition to TC intensity changes, the configurations of update_SST were turned on in both WRF experiments. This setting would allow the influence of lower boundary condition (sea surface warming) entering the atmospheric fields and thus influencing the TC intensity changes. The only different condition between both experiments is the configuration of different SST as time-independent lower boundary condition.

In both experiments, the lower boundary conditions were all provided by Microwave SST retrieved from TMI. In warming run (EXP warming), the warming patch is enclosed by a 1 degree by 2 degree rectangle box centered at the original warming patch with SST of $30.5^{\circ} \mathrm{C}$. In contrast run (EXP nonwarming), the box area of warming SST is replaced by $28.5^{\circ} \mathrm{C}$. This configuration is designed to make sure that the passage of Tembin would pass adequately through the warming and the nonwarming area for evaluating the difference from different lower boundary on TC intensity changes.

Figure 3 shows the simulated intensities evolution of Tembin retrieved from experiments EXP warming and EXP nonwarming. However, it is noted that because of the presence of a nearby strong TC Bolaven (Category 4, 20-28 August), it is very difficult to simulate the moving track of Tembin properly without nudging. The timing of Tembin passing over the warming patch is slightly different from the real situation (as shown by best-track data). Nevertheless, relative to the nonwarming scenario, with the influence of warming from lower boundary condition, the intensity 


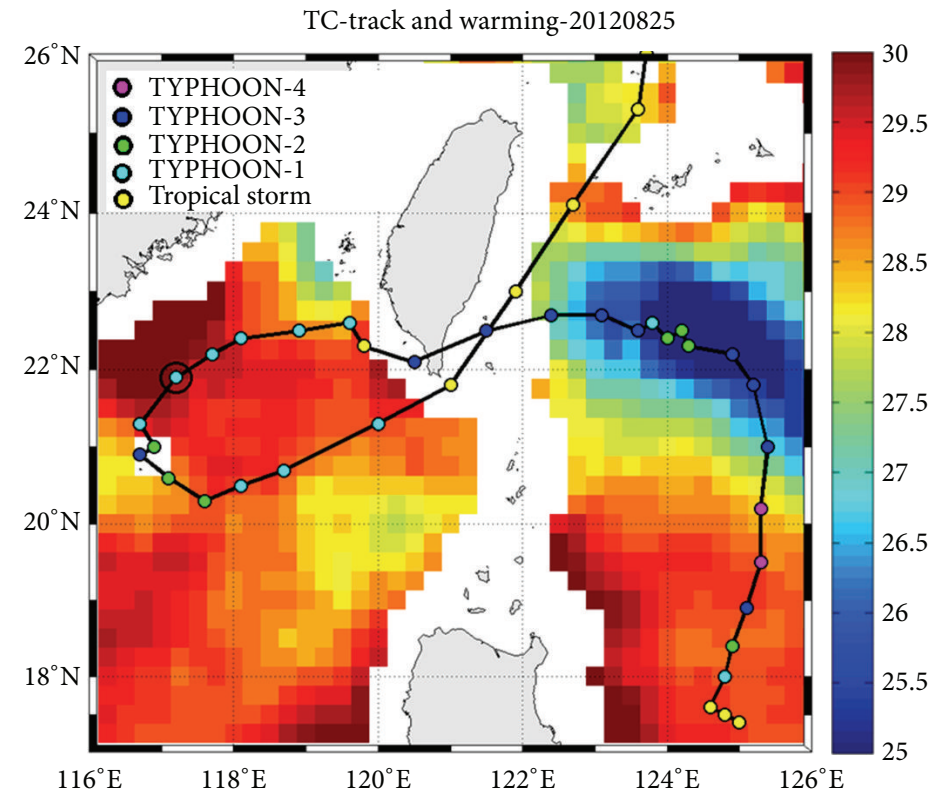

(a)

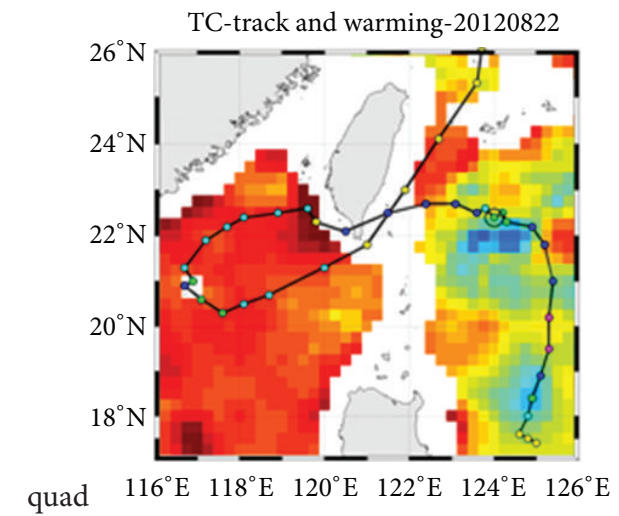

(b)

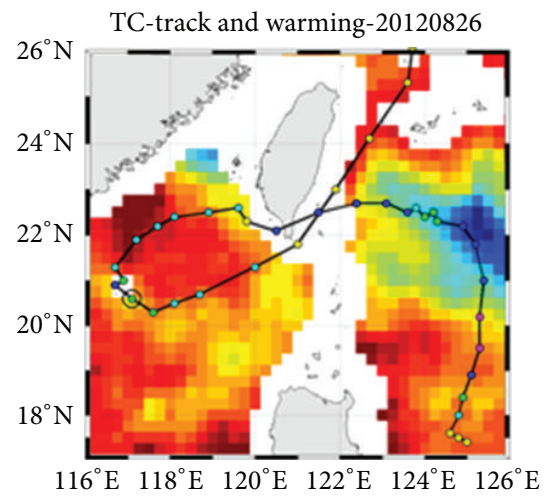

(e)

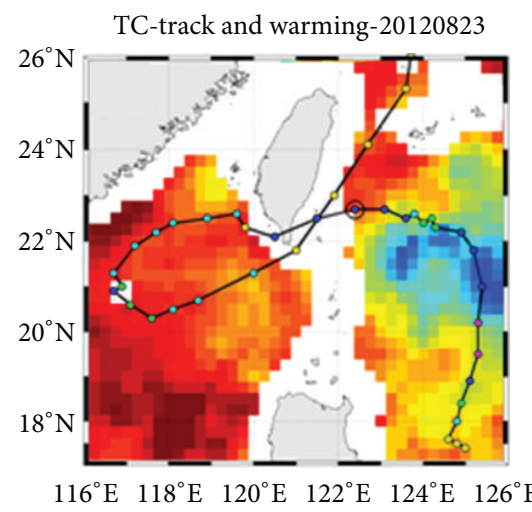

(c)

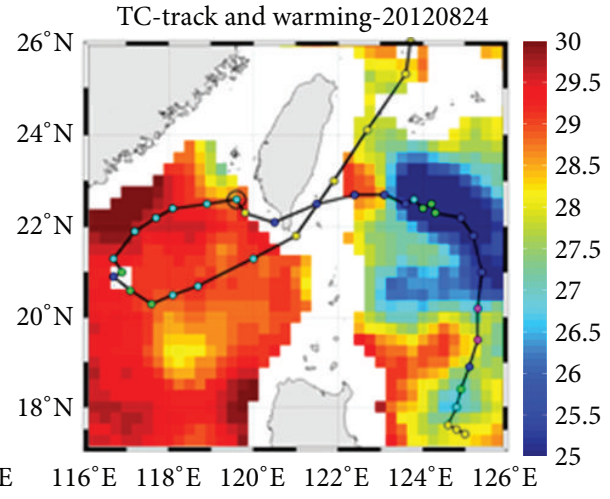

(d)

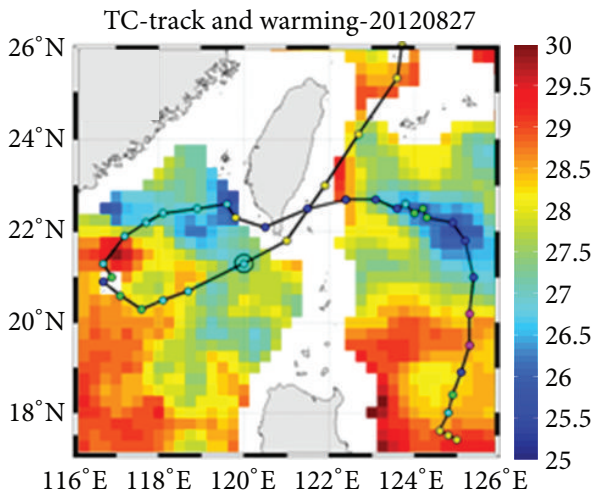

(f)

FIGURE 1: SST (unit: degree C) evolution during the generation of unusual warming patch located at the coastal region of NSCS on August 25, 2012 (a) and 22 August (b) before the rapid intensification of Tembin. Colored dots denoted the moving track and corresponding TC intensity (in Saffir-Simpson hurricane wind scale) of Tembin. 


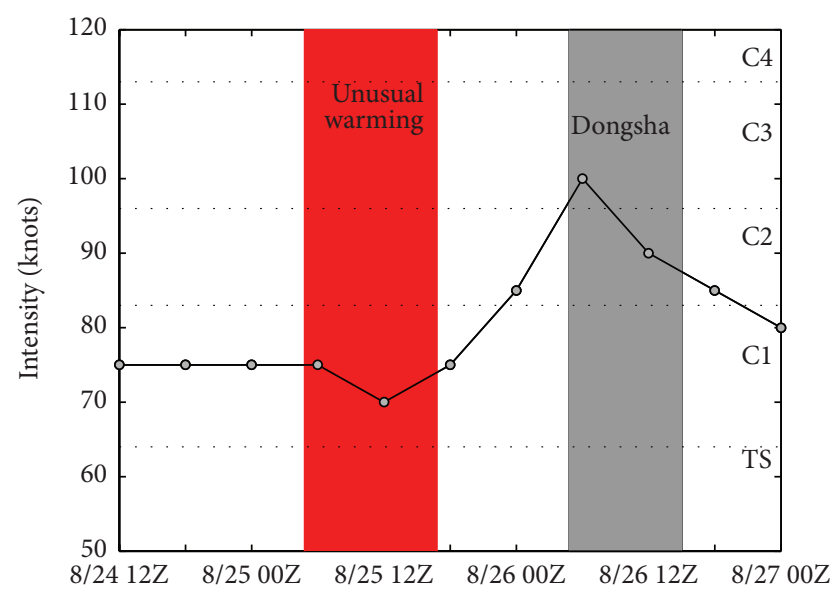

FIGURE 2: Correspondent time series of TC intensity change during Tembin's rapid intensification and following TC intensity weakening.

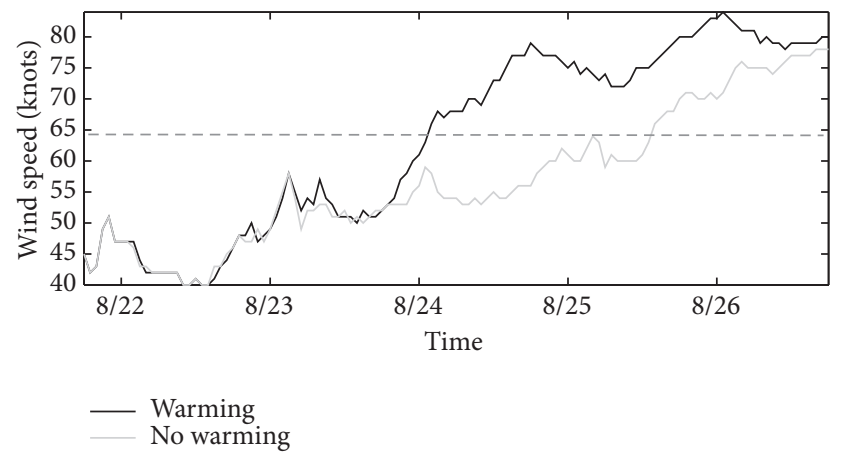

FIGURE 3: WRF simulated intensities of Tembin during the passage of warming (nonwarming) patch. Gray dashed line denotes the intensity of Category 1 in Saffir-Simpson hurricane wind scale.

changes of Tembin are well documented to show a distinct rapid intensification once it passed over the box region with different SST (warming) setting. The result derived from WRF numerical experiments identifies the causal relationship between coastal warming and consequence of TC rapid intensification. After identifying the tight relationship between them, the next key issue is to know what kinds of mechanism would cause an extreme warming in the coastal region. Given the tight relationship between warming and following possible TC rapid intensification, to get further understanding about the generation of warming in the coastal region would be very helpful for improving the TC intensity prediction in particular near the coastal region just prior to TC's landfall.

\section{What Causes the Warming in the Coastal Region of NSCS?}

Because the dynamic relationship and interactions among related variables (e.g., wind, current, topography, and airsea flux exchange) would be very hard to infer from the observations data alone, to obtain a comprehensive understanding about the generation of the extreme warming in the coastal region of NSCS, a series of numerical experiments dealing with the influence from wind, currents, and influx from atmosphere based on ROMS were designed and conducted here. First, in EXPstd, all contributions from both ocean and atmosphere were turned on to attempt to reproduce the results as well as those shown by satellite observations. Figures $4(\mathrm{a})-4(\mathrm{~d})$ show the simulated SSTs during the intensification of Tembin in EXPstd. One can see that the warming in the shore region along NSCS coast is reproduced reasonably well in EXPstd. The coastal warming disappears until the strong surface cooling response occurs after the passage of Tembin. Next, to distinguish the main contributions (key mechanism) resulting in the coastal warming, two more contrast experiments (EXP1 and EXP2) were further executed.

In EXP1, all configurations were set as EXPstd except the air-sea flux exchange which was zeroout. In EXP2, influences of TC wind forcing were removed by masking out high wind with wind speed more than $18 \mathrm{~m} \mathrm{~s}^{-1}$ from the wind field to evaluate the role of wind forcing play in this case, but all other contributions were kept as EXPstd. The threshold of $18 \mathrm{~m}^{-1}$ is decided referring to the analysis of accumulated cyclone energy for a tropical cyclone [16]. Comparing the results derived from EXP1 and EXPstd (seeing Figure 4), one can see that, without the input of sea surface heat flux (SHF), there is no longer distinct warming patch generated at the coastal region along NSCS continental shelf, though other forcings are the same as those used in standard experiment (EXPstd). This implies that the input of SHF plays a key role in the generation of this unusual warming.

Comparing results of EXP2 with those results of EXPstd, it can be seen that, without TC wind forcing (no TC wind driven currents), the warming is still revealed at similar position prior to TC passage, though cooling caused by Tembin largely decreases. This implies that the influences of removing TC wind forcing reflect mainly on the relaxation period after the passage of TC. This result dismisses the scenario of current convergence causing downwelling in the coastal region, thus prompting the coastal warming, as noted in previous studies $[12,17,18]$. In other words, there must be other mechanisms dominating the warming occurring during Tembin passage in addition to the inference proposed by Tsai et al. [12]. Nevertheless, at the same time, the key issue of "how does the warming generate?" has been narrowed to SHF exchange occurring through the air-sea interface only. In this case, wind driven current convergence plays a somewhat surprising minor role in contributing to the generation of warming. This underplay is attributed to the block of high mountain topography in the central part of Taiwan.

In ROMS, total SHF was estimated by incoming short wave radiation, outgoing long wave radiation, sensible heat flux, and latent heat flux. Here, by comparing the contributions of each heat flux terms to the total SHF in our model scheme for EXPstd, it is found that the warming patch generated in front of Tembin's passage is mainly contributed by an unusual increase of positive short wave radiation 

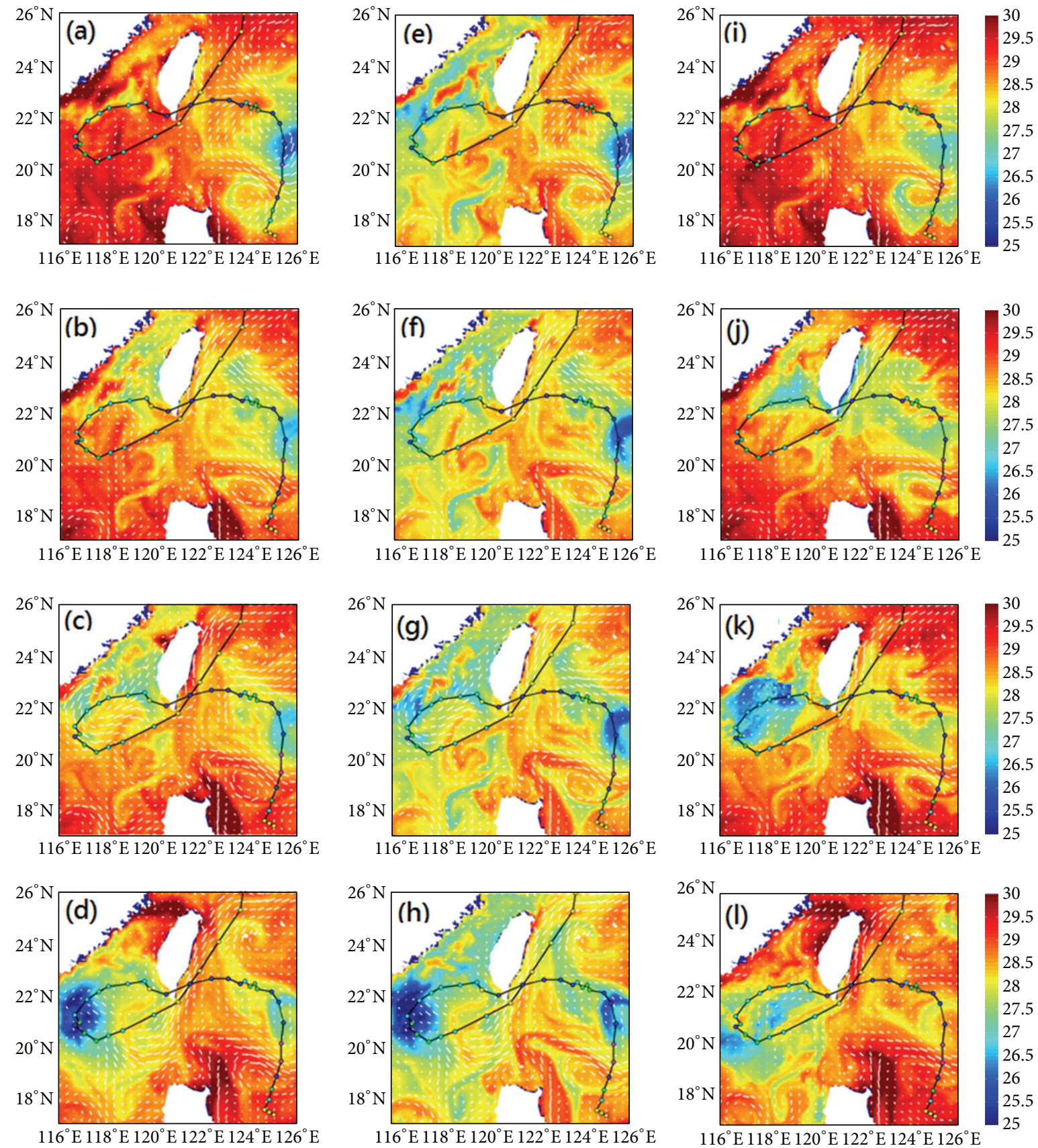

FIGURE 4: (a)-(d) ROMS simulated SST (unit: degree C) during the intensification of Tembin (23 August, 25 August, 26 August, and 28 August) in EXPstd. (e)-(h) Same as (a)-(d) but for EXP1. (i)-(l) Same as (a)-(d) but for EXP2.

anomaly which occurred on 21-22 August, two days. The impact of this short wave radiation anomaly can be seen clearly in ROMS simulated SSTs, especially on 21 August (figures not shown). Subsequently, we need to figure out the source of where this positive short wave radiation anomaly comes to answer the question of "how does the warming during Tembin's passage generate?".

Previous studies pointed out that the incoming solar (shortwave) radiation is primarily determined by latitude, season, time of day, and cloudiness [19, 20]. During Tembin's passage, the previous three factors can be taken as constant, and thus there is only one factor remaining to influence the shortwave radiation influx during Tembin's passage. Thus, we examine the evolution of cloud system prior to Tembin's passage from 21 August to 24 August. Figure 5 shows the cloud coverage from 21 August to 24 August. On 21 August, one can see the existence of a heavy cloud system over MainLand China (extending from Indochina peninsula to northeast corner of China) and another cloud system gathered by TC Tembin from a "channel-like" cloudless belt 


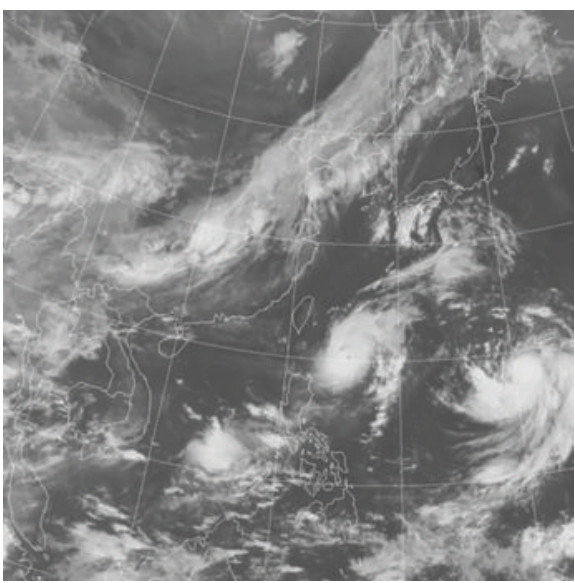

(a)

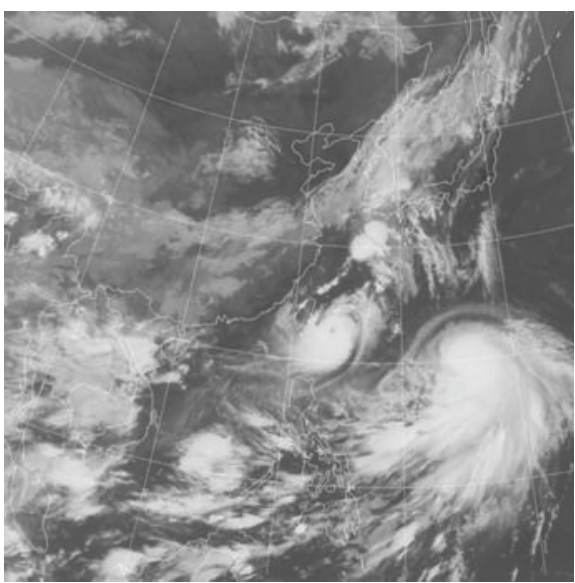

(c)

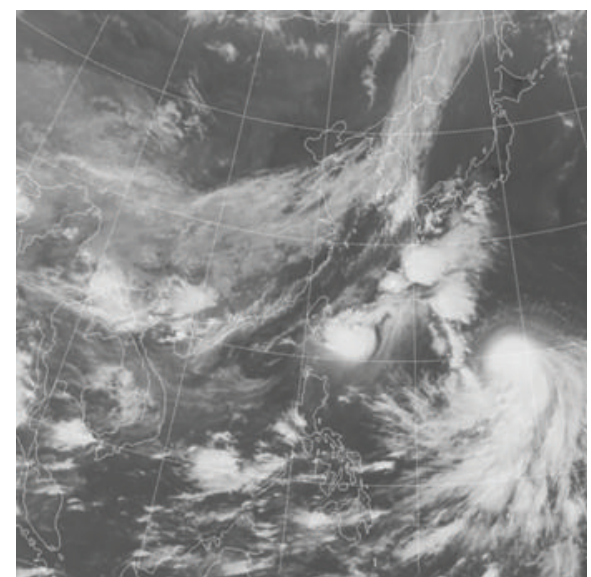

(b)

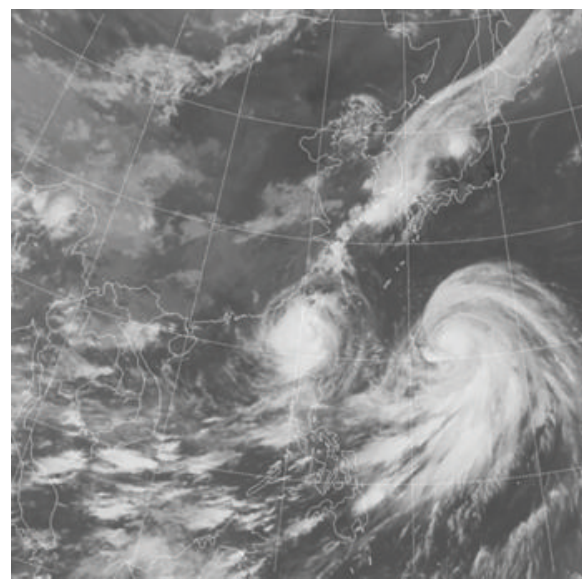

(d)

FIgURE 5: IR1_LCC images at (a) UTC $8: 32$ on 21 August, (b) UTC $8: 32$ on 22 August, (c) UTC $8: 32$ on 23 August, and (d) UTC $8: 32$ on 24 August, derived from CWB of Taiwan.

over Taiwan and Taiwan strait (TS) (seeing the channel in Figure 5(a)). On 22 August, with the approach (westward) of Tembin toward Taiwan, the cloudless belt is squeezed and getting thinner. Nevertheless, there is still a cloudless channel located over the TS and the west-half of Taiwan. Subsequently, due to the steady approach of Tembin, as a result, on 23 August, the original channel is occupied by the cloud system accompanied with Tembin's passage; meanwhile, both TS and Taiwan are covered by left part of the cloud system gathered by Tembin. On 24 August, the thick cloud system gathered by Tembin covers most parts of Taiwan and TS.

As mentioned above, in our case, incoming short wave radiation is mainly a function of cloud coverage only. Intuitively, the evolution of cloud coverage within the study area can be used to reflect the variations of amount of incoming shortwave radiation. Therefore, the results obtained from cloud coverage shown by satellite IR images in this section show somewhat surprising consistent with the inference we concluded from oceanic numerical experiments that the generation of warming in the coastal region along NSCS during Tembin's passage mainly resulted from a strong positive shortwave radiation influx anomaly.

\section{Conclusions}

In 2012, passage of Tembin over an unusual warming occurring at the coastal region along NSCS suggests a crucial scenario that a distinct warming occurring in the coastal region may booster a rapid intensification of TC intensity just prior to its landfall. This process is extraordinarily important because the generation of that warming may cause sudden intensification of TC just prior to making landfall and thus increase the threats on those people and economic activity surrounding the low-lying coastal region over the world.

In this work, we first present a rather convincing evidence based on WRF to identify the relationship between unusual sea surface warming occurring in the coastal region and consequently rapid intensification of TC intensity based on the case of Tembin (2012). The results show that the presence of unusual warming in the shore region plays a key role 
in the following rapid intensification of Tembin. Given the tight relationship between surface warming in the coastal region and consequently possible TC intensification, it is believed that the more we understand about the generation of that coastal warming, the better we can do about the TC intensity forecast especially for those sudden intensification events taking place just prior to their landfall. Next, a series of oceanic numerical experiments based on ROMS were executed to resolve the generated mechanism of those unusual warming occurring in the coastal region.

According to analyses on a series of sensitive experiments and estimation of heat budget balance in our model scheme, the generated mechanism of the extreme warming during Tembin's passage is shown to be highly associated with a distinct positive shortwave radiation influx anomaly. Accordingly, this finding is verified by the evolution of cloudless area during Tembin's passage shown by satellite IR images. This is a new and interesting process that has not been investigated adequately. Further investigations were needed to provide a more comprehensive understanding about the details of this process.

This work combines evidences and tools from ocean and atmosphere fields simultaneously, not only for identifying the tight relationship between the unusual warming in the coastal region and consequently possible TC intensification but also for shedding a new light on the process of generation of unusual warming in the coastal region. Given the possible increase of threats due to the sudden intensification of TC close to the coastal region, it is especially worth highlighting the necessity of monitoring the variations of incoming shortwave radiation nearby the coastal region in front of a TC passage through satellite IR images.

\section{Conflict of Interests}

The author declares that there is no conflict of interests regarding the publication of this paper.

\section{Acknowledgments}

This work was supported by the National Science Council of Taiwan through Grants NSC 101-2611-M-003-001 and NSC 100-2119-M-003-006. Microwave TMI SST data were provided by REMSS. Boundary conditions for ROMS derived from HYCOM/NCODA system were provided by HYCOM Consortium through http://hycom.org/. Composite infrard images were provided by Typhoon DataBase of Central Weather Bureau, Taiwan.

\section{References}

[1] J. F. Price, "Upper ocean response to a hurricane," Journal of Physical Oceanography, vol. 11, no. 2, pp. 153-175, 1981.

[2] F. J. Wentz, C. Gentemann, D. Smith, and D. Chelton, "Satellite measurements of sea surface temperature through clouds," Science, vol. 288, no. 5467, pp. 847-850, 2000.

[3] I. Lin, W. T. Liu, C.-C. Wu et al., "New evidence for enhanced ocean primary production triggered by tropical cyclone," Geophysical Research Letters, vol. 30, no. 13, pp. 51-1, 2003.
[4] N. D. Walker, R. R. Leben, and S. Balasubramanian, "Hurricaneforced upwelling and chlorophyll a enhancement within coldcore cyclones in the Gulf of Mexico," Geophysical Research Letters, vol. 32, no. 18, Article ID L18610, pp. 1-5, 2005.

[5] F. M. Monaldo, T. D. Sikora, S. M. Babin, and R. E. Sterner, "Satellite imagery of sea surface temperature cooling in the wake of Hurricane Edouard (1996)," Monthly Weather Review, vol. 125, no. 10, pp. 2716-2721, 1997.

[6] Z.-W. Zheng, C.-R. Ho, and N.-J. Kuo, "Importance of preexisting oceanic conditions to upper ocean response induced by Super Typhoon Hai-Tang," Geophysical Research Letters, vol. 35, no. 20, Article ID L20603, 2008.

[7] Z.-W. Zheng, C.-R. Ho, Q. Zheng, N.-J. Kuo, and Y.-T. Lo, "Satellite observation and model simulation of upper ocean biophysical response to Super Typhoon Nakri," Continental Shelf Research, vol. 30, no. 13, pp. 1450-1457, 2010.

[8] D. F. Leipper and D. Volgenau, "Hurricane heat potential of the Gulf of Mexico," Journal of Physical Oceanography, vol. 2, pp. 218-224, 1972.

[9] S. W. Chang and R. A. Anthes, "The mutual response of the tropical cyclone and the ocean," Journal of Physical Oceanography, vol. 9, no. 1, pp. 128-135, 1979.

[10] P. G. Black and G. J. Holland, "The boundary layer of tropical Cyclone Kerry (1979)," Monthly Weather Review, vol. 123, pp. 2007-2028, 1995.

[11] L. R. Schade and K. A. Emanuel, "The ocean's effect on the intensity of tropical cyclones: results from a simple coupled atmosphere-ocean model," Journal of the Atmospheric Sciences, vol. 56, no. 4, pp. 642-651, 1999.

[12] Y. L. Tsai, C. S. Chern, and J. Wang, "Numerical study of typhoon-induced ocean thermal content variations on the northern shelf of the South China Sea," Continental Shelf Research, vol. 42, pp. 64-77, 2012.

[13] I.-I. Lin, C.-H. Chen, I.-F. Pun, W. T. Liu, and C.-C. Wu, "Warm ocean anomaly, air sea fluxes, and the rapid intensification of tropical cyclone Nargis (2008)," Geophysical Research Letters, vol. 36, no. 3, Article ID L03817, 2009.

[14] J. A. Cummings, "Operational multivariate ocean data assimilation," Quarterly Journal of the Royal Meteorological Society, vol. 131, no. 613, pp. 3583-3604, 2006.

[15] Z.-W. Zheng, C.-R. Ho, Q. Zheng, Y.-T. Lo, N.-J. Kuo, and G. Gopalakrishnan, "Effects of preexisting cyclonic eddies on upper ocean responses to Category 5 typhoons in the western North Pacific," Journal of Geophysical Research C, vol. 115, no. 9, Article ID C09013, 2010.

[16] S. J. Camargo and A. H. Sobel, "Western North Pacific tropical cyclone intensity and ENSO," Journal of Climate, vol. 18, no. 15, pp. 2996-3006, 2005.

[17] Y. Tsai, C.-S. Chern, and J. Wang, "Typhoon induced upper ocean cooling off northeastern Taiwan," Geophysical Research Letters, vol. 35, no. 14, Article ID L14605, 2008.

[18] D. A. Mitchell, W. J. Teague, E. Jarosz, and D. W. Wang, "Observed currents over the outer continental shelf during Hurricane Ivan," Geophysical Research Letters, vol. 32, no. 11, pp. $1-4,2005$.

[19] J. A. Knauss, Introduction to Physical Oceanography, PrenticeHall, Englewood Cliffs, NJ, USA, 1978.

[20] R. H. Stewart, Introduction to Physical Oceanography, Orange Grove Books, 2009. 

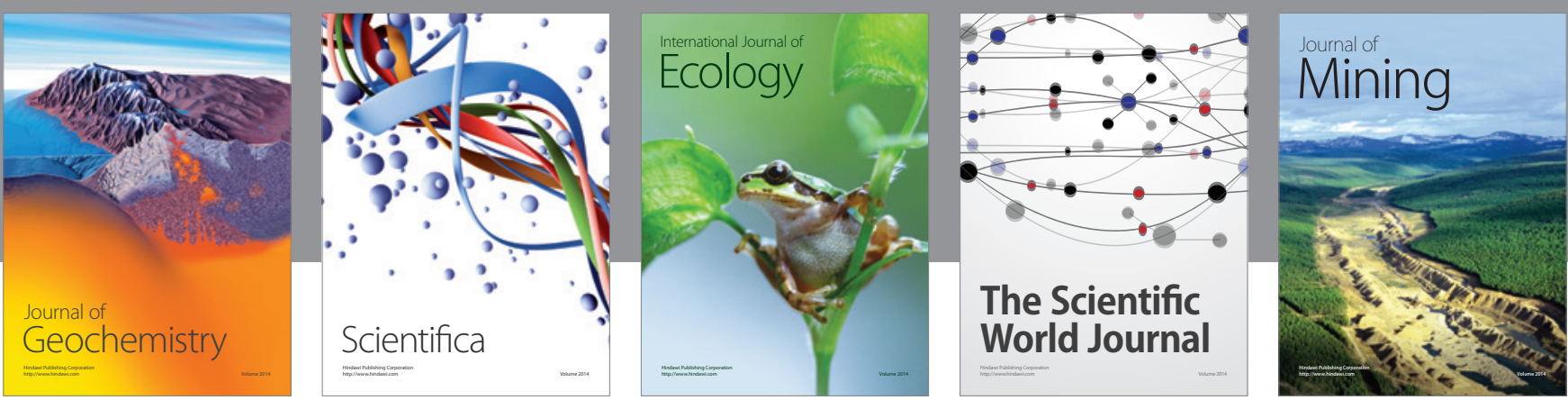

The Scientific World Journal
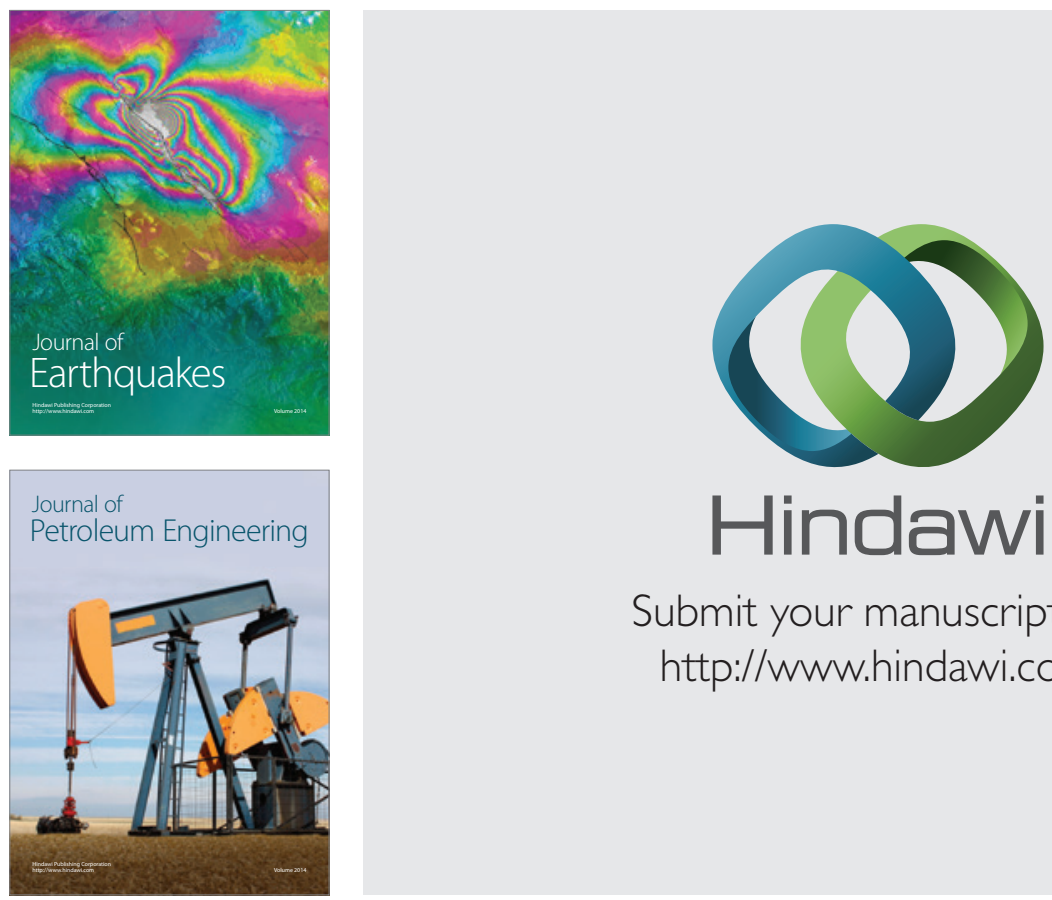

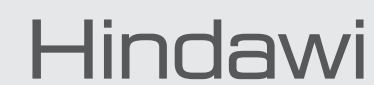

Submit your manuscripts at

http://www.hindawi.com
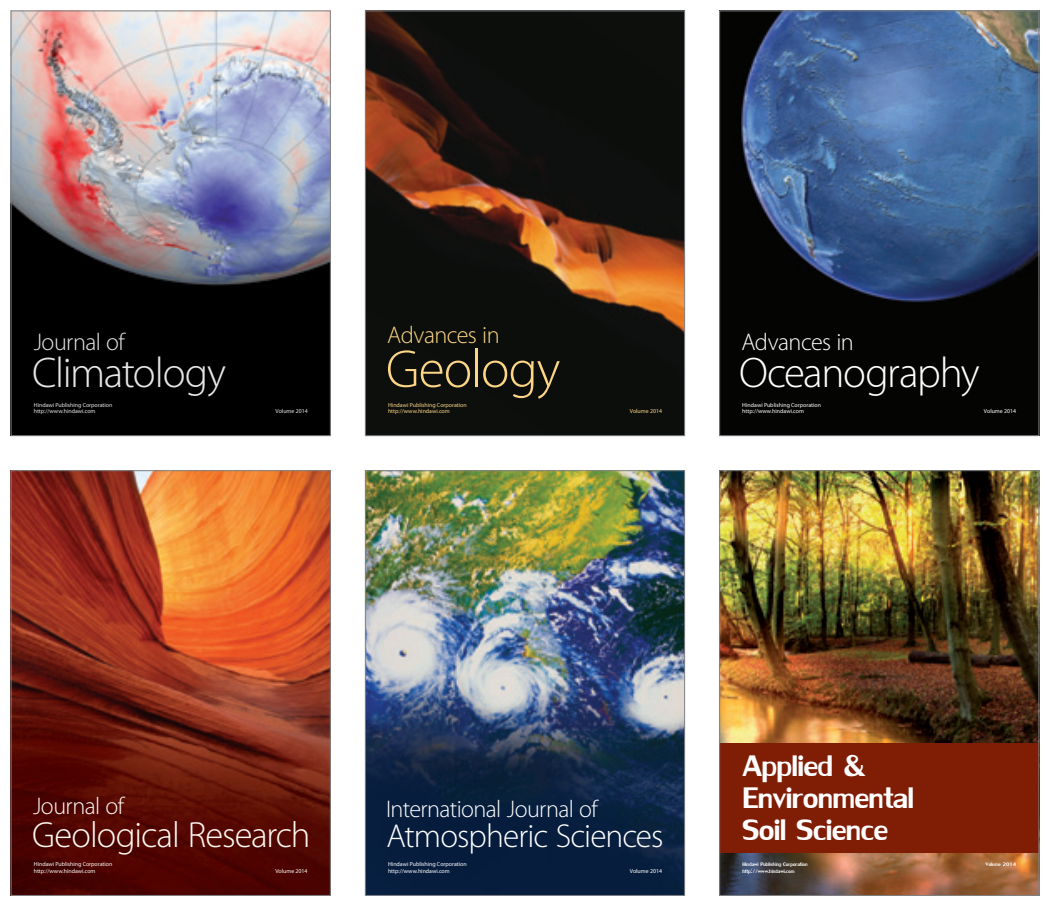
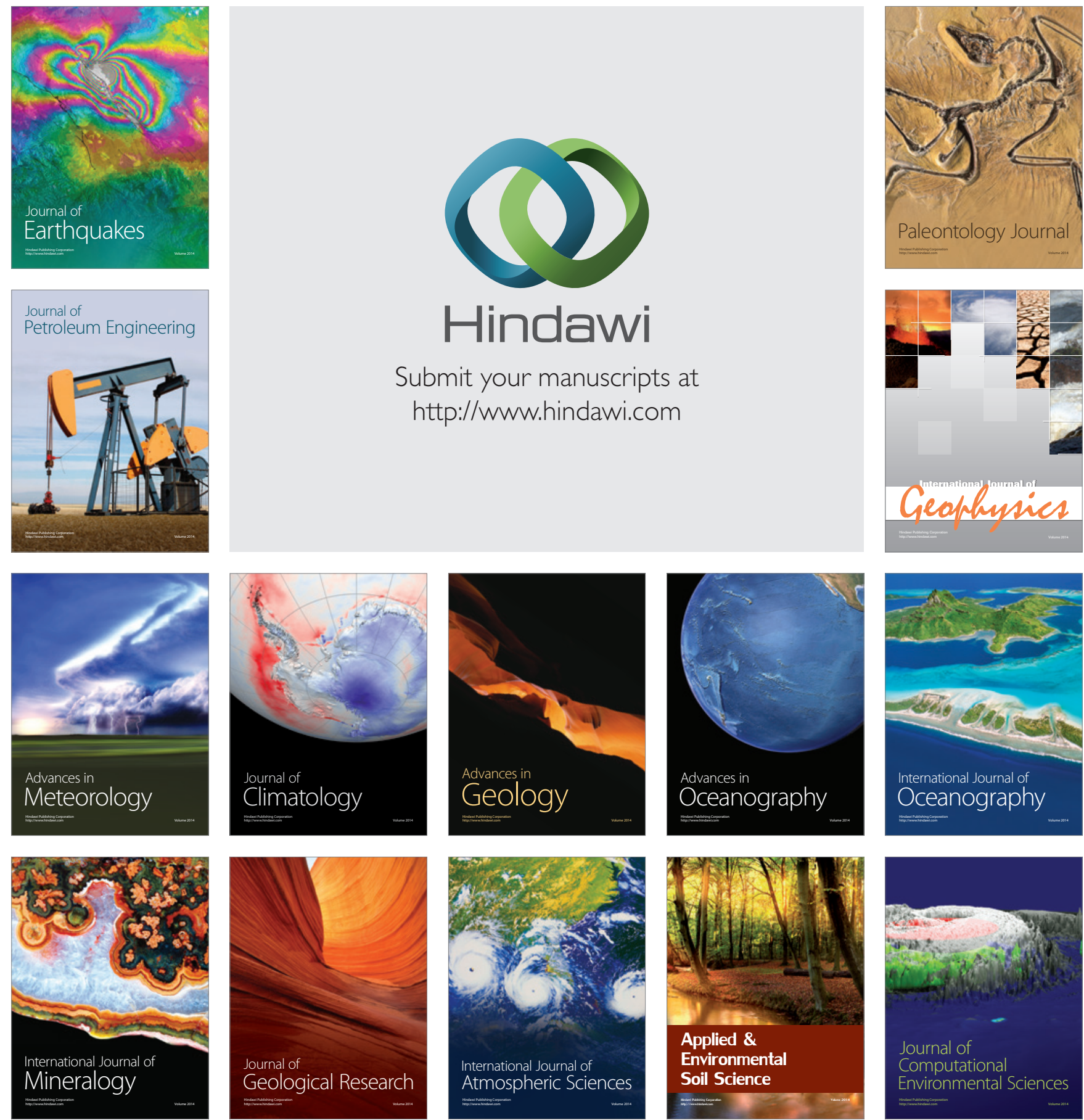